\title{
Public opinions regarding the relationship between Autism Spectrum Disorders and society: social agenda construction via science café and public dialogue using questionnaires
}

\author{
Jin Higashijima, Yui Miura, Chie Nakagawa, Yasunori Yamanouchi, \\ Kae Takahashi, Masaki Nakamura
}

\begin{abstract}
Rapid and significant developments in the science of Autism Spectrum Disorders (ASDs) have provoked serious social and ethical concerns as well as positive influences worldwide. This study created a social agenda containing 21 important issues regarding the relationship between ASDs and society and the development of the science of ASDs. The agenda was constructed with the input of a variety of Japanese people who were provided with scientific ASD information and engaged in discussions regarding ASDs. First, opinions were sought via a questionnaire from the attendees of six science café sessions. Then, additional important issues were put forward by attendees of a larger dialogue session regarding the relationship between ASDs and society, again via a questionnaire. The agenda covered a wide range of issues, including information regarding $A S D$, people's understanding of ASDs, social support, education, the difference between ASD characteristics and individuality, ASD research, diagnosis, and social attitudes.
\end{abstract}

\section{Introduction}

Science and technology wield great power in society in many ways. As with those of the past, many of the consequences of present and future advancements are and will be useful and beneficial to human society. However, some produce negative and unwanted consequences as well. For example, we have witnessed the forced sterilization of intellectually-impaired people, ${ }^{1}$ racial discrimination, ${ }^{2}$ organ farming from vulnerable people, ${ }^{3}$ and the exclusion of patients from pharmaceutical circuits in developed countries. ${ }^{4}$ These tragic and unfair cases have forced the scientific community to examine and discuss the social aspects of ongoing research and developments among a variety of people to address the social consequences as early as possible. ${ }^{5,6}$

In this process, the consideration of a variety of viewpoints is necessary. Communication between many different people and scientists ideally occurs ahead of or at least in parallel with the social consequences of a given discovery or advancement. ${ }^{5,7,8}$ This concept, i.e., the need to promote positive interactions between a given science or technology and society throughout the development process, is known as upstream engagement. 7,8

Even though the importance of upstream engagement has been relatively accepted by most of society, its implementation is quite difficult to realize. Upstream engagements are necessary in a broad range of areas associated with science and technology, particularly because our society consists of a wide range of people with varying perspectives, values, cultures, and levels of scientific knowledge. In this situation, the establishment of a perfect method to truly realize the concept of upstream engagement in reality is nearly impossible. ${ }^{8,9}$ Thus, many people and organizations are using trial and error to explore the best ways to implement this concept.

One of the most promising ways to implement the process of upstream engagement is the construction of an agenda based on the perspectives of the general public. This agenda generally involves the gathering of a variety of citizens who discuss an area of research after receiving balanced information on the topic, including its scientific aspects. One example is the 2009 World Wide Views on Global Warming, a global 
project under the initiative of the Danish Board of Technology. This event was an in-depth, global citizens' consultancy on climate change. ${ }^{9,10}$ Approximately 4,000 citizens from 38 countries participated in the dialogues within their own home countries, all following relatively similar formats on global warming. Another promising example is the ongoing mini dialogues by Sciencewise-ERC, i.e., the UK national center for public dialogue on policy making issues involving science and technology. The purpose of these mini dialogues is to gather opinions from the general public regarding certain topics in science and technology (e.g., energy, the environment, bio- and neuroscience, nanotechnology, and health). ${ }^{11}$ Moreover, in 2008, a group of Japanese researchers hosted NanoTRI, which focused on the application of nanotechnology in food products and to examine the citizens' perspectives on this topic. ${ }^{12}$ This was a hybrid event that combines three different types of events (a mini-consensus conference, group interviews, and science cafes). These three examples are challenging and notable attempts to involve not only the stakeholders who tend to have specific interests or concerns, but also ordinary people whose perspectives might be more diverse compared with that of the stakeholders.

The aim of the present paper is to construct an agenda based on people's perspectives regarding the relationship between Autism Spectrum Disorders (ASDs) and society in Japan. Scientific developments in relation to ASDs have been significantly advanced in some countries, ${ }^{13}$ including the United States, the United Kingdom, and Japan. Emerging scientific knowledge and technologies associated with ASDs could potentially have significant impacts on society; therefore, there is a real need to stimulate a variety of discussions to activate 'upstream engagement'. ${ }^{14,15,16}$ Historically, there have been a variety of interactions between the scientific community and society regarding scientific knowledge on ASDs. For example, the refrigerator mother hypothesis ${ }^{17}$ and the measles, mumps, and rubella (MMR) vaccine hypothesis. ${ }^{18}$ These were both developed from speculation regarding the cause of ASDs, and were unfortunately used to spread now discredited methods for the treatment of people with ASDs. The number of people diagnosed with an ASD is increasing worldwide. Furthermore, new diagnosis systems and scientific methods are being developed internationally to measure people with an ASD. ${ }^{19,20,21,22}$ Together, these demonstrate the level of international attention that ASD issues are receiving. This attention will in turn, either directly or indirectly, increase the research funding available for ASDs, and improve the educational system regarding ASDs in some countries.

\section{General description of Autism Spectrum Disorders}

ASDs are a group of lifelong, neuro-developmental disorders that are diagnosed by behavioral aspects. ${ }^{23}$ Approximately one percent of people worldwide are medically diagnosed as having an ASD. ${ }^{24,25}$ Beyond the number of individuals who have an ASD, a much larger percentage are directly or indirectly associated with an ASD, whether as family members, neighbors, colleagues, classmates, educators, clinicians, doctors, or social service providers. For society as a whole, the economic costs of ASDs are relatively high, although individuals and families with an ASD may not have the appropriate supports in their society. ${ }^{26}$ Autism, Asperger Syndrome, and Pervasive Developmental Disorder-Not Otherwise Specified are the main disorders under the umbrella of ASDs. ${ }^{1}$

\section{Science of Autism Spectrum Disorders and society}

Research associated with ASDs is a very active field, and attract huge sums of money worldwide. This is because of the social needs surrounding ASDs and the academic importance of the science of ASDs in terms of understandings human biological functions. ${ }^{27}$ Researchers currently define ASDs based on various behavioral characteristics described in common medical diagnoses ${ }^{23,28}$ and continually attempt to establish valid biological markers for ASDs. However, researchers have not yet been able to identify any widely effective and useful biomarkers that are clinically effective in practice to definitively identify people with ASDs, nor have they developed specific medical treatments effective for all people with ASDs.

Indeed, the science of ASDs has interacted with society for more than half a century. ${ }^{17}$ One of the most powerful impacts is the emergence of and changes in the scientific definitions for ASDs as they play crucial roles in identifying people with a specific ASD. Since the reporting of 'early infantile autism' by Kanner (1943) and 'autistic psychopathy' personality disorder by Asperger (1944), the classification of 
people with what are now called ASDs has changed several times. ${ }^{17}$ Changes in society that correspond to changes in the definition of ASDs may function to tangibly improve education, social services, systematic diagnoses, and therapies for individuals who have been diagnosed with an ASD. However, the opposite may also be true; i.e., these changes could possibly reduce the quality of the aforementioned ASD support systems. In terms of less visible dimensions, social attitudes toward individuals with ASDs and their families may gradually change in accordance with changes to the definitions associated with ASDs. Although social discrimination may result from the fact that an individual is diagnosed as having an ASD, actually having the diagnosis can be effective in helping that individual construct good relationships with their colleagues, families, friends, all of whom may have a better understanding of ASDs due to the emergence of these definitions. Although science and technology might not always be linked to or result in direct impacts on human life, we can still see their fingerprints on our culture, economic and legal systems, and on other areas all around us.

Despite the serious potential impacts of the science of ASDs on human society, there still lacks a serious consideration of the ethical and social aspects of the science of ASDs; indeed, it is only recently that it has been recognized as important. ${ }^{14,15,16,29}$ As a result, some interesting discussions regarding the ethical and social aspects of the science of ASDs have taken place among scientists, practitioners, ethicists, parents, and/or people diagnosed with an ASD. However, these discussions do not include opinions from the general public. Moreover, the majority of these discussions have been held in the United Kingdom and the United States, where a considerable level of social attention has been placed on ASDs. ${ }^{15,16,29}$ In other countries, the ethical and social aspects of the science of ASDs remains seemingly unexamined, even though the science of ASDs has been developed on a worldwide basis, with global developments that are changing people's lives. In principle, it is important to take a range of cultural diversity into account when considering the ethical and social aspects of a given field of science. Thus, discussions regarding the ethical and social aspects of the ongoing science of ASDs are required in countries other than the United Kingdom and the United States.

\section{Aim of our research}

As mentioned previously, the purpose of this paper is to develop a social agenda based on collaboration among a variety of people, focusing on the relationship between society and ASDs in Japan. The methods used to gather opinions and information regarding ASDs will be carefully described because the content of an agenda tends to be influenced by the way in which the information is gathered and analyzed. When developing the agenda, we tried to include a variety of people, ranging from individuals who had no direct relationship with ASDs to individuals who have been diagnosed with an ASD or have a family member with an ASD. As the impacts of the science of ASDs may be wide-ranging in society, a variety of people may be consciously or unconsciously influenced by it. Therefore, we attempted to include a wide range of people in our discussion. We also tried to provide up-to-date, understandable, scientific information regarding ASDs because the science of ASDs has influenced the relationship between ASDs and society, as previously described. Moreover, we required all the participants in our research to engage in a dialogue with various participants, including ASD researchers, at the opinion-gathering stage. This is based on the idea that it is necessary to allow participants to listen and ask their own questions in such discussions to truly grasp many different viewpoints. ${ }^{9}$ Once a pre-agenda was created using the results from the questionnaire, this document was reviewed by a variety of people to give them a chance to present additional points (see the Methods section for further details). We expect that this agenda, which was created by a variety of people in Japan, to be the basis of ongoing discussions concerning the improvement of the relationship between ASDs and society.

\section{Methods}

The agenda was designed via three steps (figure 1). In the first and second steps, a pre-agenda was created using classified answers from questionnaires that were distributed after six mini dialogues concerning ASDs. During the third step, additional issues were obtained using a questionnaire containing the pre-agenda. 


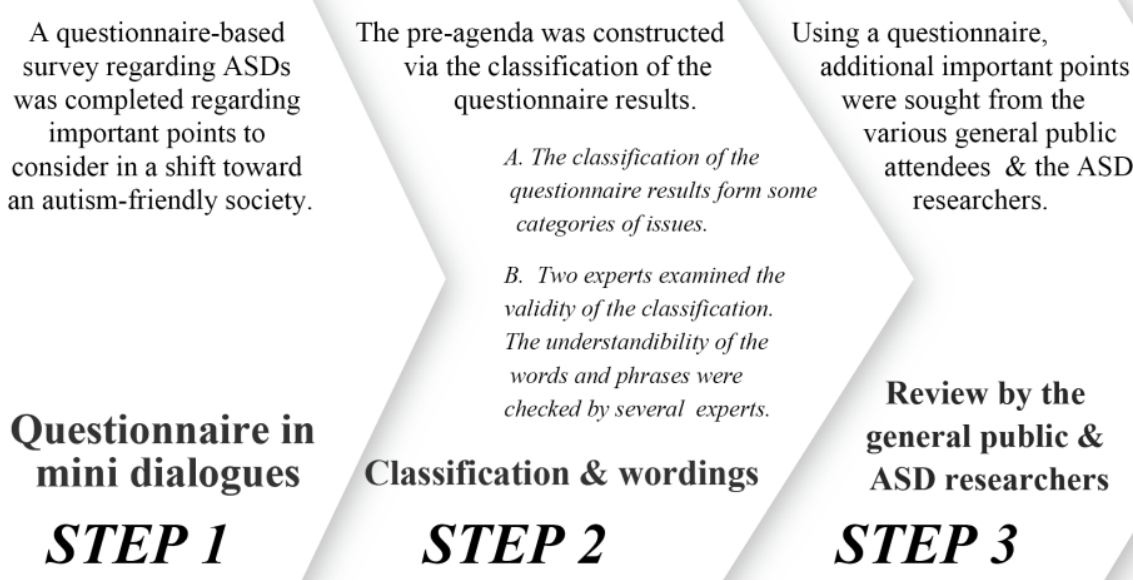

Figure 1. Three steps of agenda construction.

1) Step 1. Mini dialogues and questionnaire: after mini science café dialogues regarding ASDs, questionnaires were used to collect the opinions of a variety of people. There were five mini dialogue formats involving a range of attendees (table 1). The format used to present the scientific information at each dialogue varied for each session. The researchers who gave a talk at each mini dialogue (10 $\mathrm{min}$ at dialogue $3 ; 20 \mathrm{~min}$ at dialogues 4,5 , and 6) as well as the content of each talk were different each time, although all of the researchers were asked to clearly provide scientifically valid, balanced, and relatively up-to-date information.

\begin{tabular}{|c|c|c|c|c|c|c|}
\hline Event type & Attendees & Recruitment & Scientific information & Duration & Dialogue type & $\begin{array}{c}\text { Number of } \\
\text { effective answers }\end{array}$ \\
\hline \multirow{2}{*}{$\begin{array}{l}\text { Monthly science } \\
\text { café } \\
\text { mini dialogue } 1 \& 2\end{array}$} & $\begin{array}{l}36 \text { concerned } \\
\text { people* including at } \\
\text { least } 4 \text { ASDs } \\
\text { researchers }\end{array}$ & \multirow{2}{*}{$\begin{array}{l}\text { People who were } \\
\text { interested in a science } \\
\text { café dialogue } \\
\text { regarding ASDs }\end{array}$} & \multirow{2}{*}{$\begin{array}{l}\text { Available at anytime, if required } \\
\text { or questioned by attendees }\end{array}$} & \multirow{2}{*}{$\begin{array}{l}2 \text { hours (free } \\
\text { to come \& } \\
\text { go, anytime) }\end{array}$} & \multirow{2}{*}{$\begin{array}{l}\text { Group talk: each group } \\
\text { included approximately } \\
5 \text { people and at least } 1 \\
\text { ASDs researcher }\end{array}$} & \multirow[t]{2}{*}{33} \\
\hline & $\begin{array}{l}20 \text { concerned } \\
\text { people* including at } \\
\text { least } 4 \text { ASDs } \\
\text { researchers }\end{array}$ & & & & & \\
\hline $\begin{array}{l}\text { Fathcrs' scicncc } \\
\text { café dialogue } \\
\text { mini dialogue } 3\end{array}$ & $\begin{array}{l}7 \text { fathers of (a) } \\
\text { child(ren) from a } \\
\text { nursery, a teacher, } \\
\& 2 \text { nursery } \\
\text { administrators }\end{array}$ & $\begin{array}{l}\text { Handouts disseminated } \\
\text { in a nursery, \& a } \\
\text { private network among } \\
\text { those who were } \\
\text { interested in ASDs }\end{array}$ & $\begin{array}{l}\text { Provided before the dialogue, } \\
\text { approximately } 10 \mathrm{~min} . \mathrm{Q} \& \mathrm{~A} \\
\text { were always available during the } \\
\text { dialogue }\end{array}$ & 2.5 hours & $\begin{array}{l}\text { Group talk: each group } \\
\text { included } 5 \text { people }\end{array}$ & 10 \\
\hline $\begin{array}{l}\text { Mothers' discussion } \\
\text { mini dialogue } 4\end{array}$ & $\begin{array}{l}44 \text { mothers of (a) } \\
\text { child(ren) from a } \\
\text { nursery \& } 5 \text { ASDs } \\
\text { researchers }\end{array}$ & $\begin{array}{l}\text { Participants were } \\
\text { recruited by a nursery } \\
\text { as part of their } \\
\text { discussion week } \\
\text { notification }\end{array}$ & $\begin{array}{l}\text { Available at anytime. There was } \\
\text { one long ( } 20 \text { min.) \& } 3 \text { short } \\
(1 \text { min.) prescntations before the } \\
\text { dialogue. Q \& A were always } \\
\text { available during the dialogue }\end{array}$ & 2 hours & $\begin{array}{l}\text { Discussion among } \\
\text { all attendees }\end{array}$ & 44 \\
\hline $\begin{array}{l}\text { Childcarer' science } \\
\text { café } \\
\text { mini dialogue } 5\end{array}$ & $\begin{array}{l}9 \text { emplyees from } \\
\text { a daycare service } \\
\& \text { an ASDs } \\
\text { researcher }\end{array}$ & $\begin{array}{l}\text { Requested by a } \\
\text { childcare company } \\
\text { (no recruitment) }\end{array}$ & $\begin{array}{l}\text { Provided before dialogue }(20 \mathrm{~min} \text {.). } \\
\text { Q \& A were always available } \\
\text { during the dialogue }\end{array}$ & 2 hours & $\begin{array}{l}\text { Discussion among } \\
\text { all attendees }\end{array}$ & 9 \\
\hline $\begin{array}{l}\text { Students' group } \\
\text { discussion } \\
\text { mini dialogue } 6\end{array}$ & $\begin{array}{l}\text { Approximately } \\
30-40 \text { university } \\
\text { students** }\end{array}$ & No recruitment & $\begin{array}{l}\text { Provided before dialogue }(20 \mathrm{~min} .) \text {. } \\
\text { Q \& A were always available } \\
\text { during the dialogue }\end{array}$ & 1.5 hours & $\begin{array}{l}\text { Group discussion: } \\
\text { each group included } \\
\text { approximately } 5 \\
\text { students }\end{array}$ & 33 \\
\hline
\end{tabular}

* The number of attendees may be slightly higher because people could come and go as they wanted.

** The number of student attendees may be slightly higher because they were free to come and go as they wanted.

Table 1. Six science café dialogues. 
General description of mini dialogues and questionnaire. It was free to attend the mini dialogues, and drinks (coffee or tea) and some sweets were provided, except for mini dialogue 6, which was held in at a lecture in a university. Before each dialogue, there were short talks concerning the scientific aspects of ASDs, followed by a free-form discussion/conversation between the ASD researcher(s) and participants. At the end of each dialogue, an anonymous questionnaire was distributed. The questionnaire contained the following two questions: (1) Towards the construction of an autism-friendly society, what is the most impressive/important thing for you after finishing the conversation in today's café discussion? Every answer is welcomed, for example, important issues, difficulties, and necessary points. Note that you can only point out one thing. (2) Please explain the background, and/or the reason for your answer to the previous question. The sole purpose of question (2) was to make the interpretation of the answers to question (1) clearer and more accurate, to gain supplementary information for the coding process in Step 3. The questionnaire also stated that the results of the questionnaire were to be used in a larger dialogue regarding the science of ASDs and society (described in Step 3). ${ }^{12}$ The format of our questionnaire was modeled on that used in Yagi and Nakagawa (2011). ${ }^{30}$ All the mini dialogues were held between May and August 2010.

Mini dialogue 1 and 2. These dialogues were held in the city center of Kanazawa, Japan, as a monthly science café targeting ASDs. The sessions were organized by a research group entitled "Toward an Autism-friendly Society: dialogue on science \& ethical, legal, social, and economical issues concerning Autism Spectrum Disorders; TAS (Chair, Professor Oi Manabu)". ${ }^{31}$ The concept of the monthly café was to provide a platform and occasion for dialogues to a broad range of citizens who were interested in ASDs for various reasons, accompanied by researchers whose fields of research included ASDs. All citizens were welcomed, from individuals who were simply curious about ASDs to those who were particularly concerned about ASD difficulties in their daily lives. For that reason, the café was held in the city center area beside a beautiful, green garden to make the atmosphere of the café comfortable and the starting time changed every month to ensure accessibility for a variety of people. Almost all topics regarding ASDs were welcomed, except for highly specific, personal counseling-like discussions that were not suitable for dialogue among a general group. The café schedule was disseminated to interested parties via a number of mailing lists covering ASD-related topics, leaflets placed in various ASD-related organizations, the café's weblog, and a variety of private communications. In addition, a local newspaper covered an upcoming monthly café meeting on one occasion.

The discussions at the monthly cafés, usually within a small group of three to seven people per table, were loosely facilitated by a main facilitator. This facilitator would start the session, advise when it was time to take a break, when to change seats (twice in each session), and end the café session. At the beginning, the facilitator ensured that the people at each table were on an equal footing, were equally respected, and were instructed not to use words or titles that would denote their position or social status, such as professor or teacher, during the dialogue. At least one researcher (who studies ASDs to some extent) was seated at each table; herein, called "today's researcher(s)." Today's researchers changed their places every 30 minutes to allow participants to engage in conversation with a variety of researchers. Today's researchers were asked beforehand by the main facilitator to keep the atmosphere of their table friendly and comfortable to ensure that everyone joined in the dialogue. At the center of the café room, there were white or black boards with posters containing self-portraits and hand-written information regarding today's researchers, including self-written profiles with their name, interests, future dreams, or their childhood dreams. This information was intended to make the dialogue friendly and informal.

In mini dialogues 1 and 2, all of the information regarding ASDs was provided by today's researcher(s) as part of the conversations at each table. In other words, no standard content for the scientific information was provided.

Mini dialogue 3. The attendees at this dialogue were the fathers of nursery children, teachers, and the head teacher of a private nursery school. All ten attendees were male. Some were asked to participate in the session via private communications and others came after seeing a leaflet advertising the session. Some had a child or children with an ASD or their child/children were considered to have a borderline ASD. After a short introduction among the attendees, an ASD researcher provided an approximately 10minute presentation regarding the scientific aspects of ASDs using hand-drawn pictures. The presentation concisely described the medical, biological, psychological, and educational aspects of ASDs. For example, the percentage of people with an ASD and the typical childhood behavioral characteristics were discussed. Then, participants were separated into two groups to discuss the relationship between ASDs 
and society with a facilitator. We used a modified version of Yagi and Nakagawa's (2011) method to promote their discussions. One of the main modifications was that there were two ASD researchers (ethics and psychology, language and psychology) available during the discussion, walking between tables so that participants were free to ask questions. The other difference was that after the discussions, followed by short presentations by one member from each group to share the group outcomes, there was a general discussion that included the researchers and an additional researcher with a major in education. The total duration of the café session was approximately 2.5 hours.

Mini dialogue 4. Participants of this dialogue included 44 mothers of children in a nursery school who were interested in discussions regarding ASDs. Some of their children had disabilities including ASDs or were considered to have a borderline ASD. This nursery school has annual discussion weeks to discuss a variety of issues and the mini dialogue was held as a part of a discussion week. In this dialogue, all the participants sat at a single table. There was a facilitator to promote discussion. At first, a senior leading researcher in ASD research gave a short 15-minute talk using PowerPoint. Then, three ASD researchers also gave short talks around 1 minute each, followed by a general discussion to consider various aspects of ASDs.

During the 15-minute talk, the medical and biological aspects of ASDs were described. The main focus was on molecular biology, but basic medical and biological information regarding ASDs (e.g., definition and behavioral characters) were also presented. The other three ASD researchers' mini talks mainly covered their own research including psychology, ethics, sociology, and education.

Mini dialogue 5. Nine members of a childcare company attended this dialogue. This dialogue was offered in response to a request from the company to give their members a better understanding of children with an ASD. After an approximately 20-minute presentation by an ASD researcher regarding ASDs, all the participants came together to discuss the various aspects of ASDs. During the 20-minute presentation, basic topics in the fields of psychology, medicine, and biology (e.g., childhood behavioral characteristics and clinical definitions) were briefly illustrated.

Mini dialogue 6. This group discussion dialogue, concerning the relationship between science and society, was carried out in a dialogue class at a four-year university. Because students were basically free to come and go at any time (but nearly all stayed for the discussion), the total number of attendees remains unknown, but at least 33 students attended. Before the class, information regarding ASDs was made available via reading materials. During the class, an ASD researcher gave a 20-minute presentation regarding the science of ASDs, followed by a 10-minute question-and-answer time. After the presentation, students discussed the issues surrounding the science of ASDs. At the end of their class, each group of students was required to make a small presentation that briefly described the results of their discussions. After the presentations, students were asked to answer a questionnaire that was very similar to those used in mini dialogues 1-5, but also included a place to fill in their names to count their attendance. The researcher who gave the presentation also told the students that the questionnaire was not a requirement for class credit. After the class, the questionnaire was collected and separated into two parts, the questionnaire and students' names; in other words, the students' names were removed from the questionnaires by the professor in charge of the class. In the 20-minute presentation, psychological, medical, biological, ethical and sociological aspects of ASDs were discussed. For example, changes in ASD diagnosis numbers worldwide, changes in medical definitions, and the behavioral characteristics of people with ASDs were described.

2) Step 2. List construction: in this stage, all the questionnaires were classified to construct a draft version of our agenda. Then, various experts examined the validity of the classification, wording, and phrases.

First, three coders scrutinized each questionnaire (two researchers and a graduate student). Thus, each questionnaire was always coded three times by three coders. Though our questionnaire asked respondents to point out the most impressive or important issue towards the construction of an autism-friendly society, there were some respondents who provided more than one important point. In the scrutinizing process, all the important points from a questionnaire were written down separately on small sticky notes. If there were three points mentioned in a questionnaire, then a coder made three sticky notes for that questionnaire. After being coded by one coder, the questionnaire was passed to another coder. If the next coder found another important point in the questionnaire, then the coder added another sticky note. 
Throughout the coding process, each coder was prohibited from peeling off any sticky notes pasted by the other coders.

After all the questionnaires were coded, all the sticky notes were numbered and peeled off for categorization. The numbers on the sticky notes were also written on each questionnaire, which referred to the original questionnaires, if needed during the process of classification. The sticky notes were classified in correspondence with their contents by the three coders into categories. It was intended that the maximum number of categories (items included in the agenda) would not go beyond 50. After agreement between coders, the categories were titled to reflect their content to make a list of categories, thus creating the draft version of the agenda. The validity of categorization and the definitions/meanings of words and phrases were examined by two experts in science communication and public dialogue. These people were familiar with the basic concepts of ASDs. A number of TAS members then reexamined the pre-agenda created by this process to check its understandability.

3) Step 3. Review process using a questionnaire: in this step, a pre-agenda-based questionnaire was used to enable various people to address additional points. The questionnaire contained pre-agenda issues, and asked people to choose 10 important points worth discussing among various citizens. If participants found further important issues worthy of discussion (maximum of two), then they could include them in the questionnaire. The additional points addressed by respondents were examined and classified by the classifiers, according to the same classification procedure in Step 2. If a proposed point was not included in the existing agenda, then a new category was made to represent that point.

The questionnaire was distributed to 78 scheduled participants of a 3-day dialogue entitled "Autism dialogue: Messages from citizens for scientists and society". This event was held in Kanazawa, run by TAS [further details are described in Higashijima, Nakagawa et al. (2012)]. ${ }^{14}$ The questionnaire was designed to serve the following three purposes: 1) to present research to make an agenda; 2) as reference materials for the classification of participants into sub-groups for the discussion part of the 3-day dialogue; and 3) as material for an ice breaker at the beginning of the sub-group discussion. ${ }^{12}$

The first day of the 3-day dialogue was used to present information on ASDs, and the other two days were used for discussions. The presentation day mainly focused on scientific information regarding ASDs through eight specific presentations (i.e., Introduction to ASDs, Diagnoses and Therapy, Gene, Brain, Society, Education, Labor, and Aged People) by researchers belonging to various universities. A short presentation on the development of equipment to measure the brain activity of people with ASDs, and a talk by an individual who considered himself autistic were also given. After each presentation/talk, a short question-and-answer session was provided.

The questionnaire was sent out to participants via postal mail a few weeks before and after the first day of the dialogue, and a stamped, self-addressed envelope was included for the return of the completed questionnaire. When requested, questionnaires were also sent via email. In both cases, the questionnaire and responses were not anonymous.

Dialogue participants consisted of citizens with varying backgrounds who had been chosen from a pool of applicants, or those invited by its organizing committee: individuals with an ASD, entrepreneurs, parents with young children, industry researchers engaging in ASD-related medical equipment, elementary or high school principals, artists associated with museums or art universities, journalists, university students, presidents and vice presidents of four-year universities, and people involved in education and public welfare. Researchers engaged in various ASD research also participated, and many were members of TAS. Among the participants, at least 30 people belonged to universities as students, researchers, office staff, or executives. Most of the participants lived in or around the Kanazawa area.

\section{Results}

Questionnaires: one hundred and fifty questionnaires were collected in Step 1. One blank questionnaire was excluded from further analysis. Six questionnaires were excluded from classification in Step 2 because the coders regarded their content as not relevant to the questions. It seems some respondents answered more than once on different occasions by attending different dialogues. As our purpose was to collect various points of views, it was deemed worthwhile to use all the questionnaires expressing different experiences in our agenda-building process. 
In Step 3, 82 useable questionnaires were collected. The questionnaires were completed by the following respondents: four by executives from four-year universities, seven by entrepreneurs, eight by people who belonged to a museum or art university, six by parents of one or more children without an ASD, five by people with ASD, two by the general public, three by teachers at special education schools, four by journalists, four by industrial researchers, five by students at four-year universities, three by students at graduate school, nineteen by people belonging to public service organizations, one by a principal of a high school, one by a member of a patient group, and ten by researchers engaging in ASDrelated research. In Step 3, 28 respondents answered twice. There were a few questionnaires completed by respondents who did not attend the presentation day. However, all questionnaires were taken into account because the aim of this step was to include further important points to the agenda.

Agenda: a list of the important points deemed necessary to discuss among a variety of people are shown as an agenda in table 2. The points addressed at the mini dialogues are numbered 1 to 19 ; additional points offered via the questionnaire in Step 3 are numbered 20 and 21.

\begin{tabular}{|c|c|}
\hline 1 & Public service: for people with ASDs \\
\hline 2 & Public service: for families with members with an ASD \\
\hline 3 & $\begin{array}{l}\text { Understanding people with ASDs and forming relationships with them: a good understanding about } \\
\text { the individual characteristics of individuals with an ASD and a good relationship between people } \\
\text { with ASDs and the people around them }\end{array}$ \\
\hline 4 & $\begin{array}{l}\text { Education and support regarding people with ASDs: education and support corresponding to the } \\
\text { individual differences of people with ASDs (child and/or adult) }\end{array}$ \\
\hline 5 & $\begin{array}{l}\text { Understanding families living with ASDs and forming relationships with them: a good } \\
\text { understanding about the families of people with ASDs, and good relationship-building between } \\
\text { the families and people around them }\end{array}$ \\
\hline 6 & $\begin{array}{l}\text { Communication methods: how to communicate knowledge and information regarding ASD to } \\
\text { society to create a better social understanding of ASDs }\end{array}$ \\
\hline 7 & $\begin{array}{l}\text { Contents of the information: what information regarding ASDs is necessary for society to } \\
\text { better understand ASDs? }\end{array}$ \\
\hline 8 & $\begin{array}{l}\text { Influences of the dissemination of ASD-related information in society: what are the consequences } \\
\text { of the dissemination of knowledge regarding ASDs throughout society? }\end{array}$ \\
\hline 9 & $\begin{array}{l}\text { Target of the information regarding ASDs: whose understanding of ASDs is considered } \\
\text { important/necessary? }\end{array}$ \\
\hline 10 & $\begin{array}{l}\text { Other problems in the field of the understanding of and knowledge regarding ASDs in society } \\
\text { (problems not mentioned in 6-9) }\end{array}$ \\
\hline 11 & ASDs research in general, except for the issues mentioned in 12 \\
\hline 12 & ASDs research for a cure for ASD \\
\hline 13 & Advantages and disadvantages of ASDs diagnosis \\
\hline 14 & Ambiguity and difficulty of diagnosis/definition of ASDs \\
\hline 15 & $\begin{array}{l}\text { The difference between ASD characteristics and indivduality: is an ASD a disease or part of a } \\
\text { person' s individuality? }\end{array}$ \\
\hline 16 & Discussion and dialogue regarding ASD among various people in the society \\
\hline 17 & Social and public view/attitude toward people with ASDs \\
\hline 18 & ASDs and discrimination \\
\hline 19 & Culture, atmosphere and attitudes: social acceptance of each individual regardless of disabilities \\
\hline 20 & Balancing the "cure for ASDs" and the "co-existence of people with and without ASDs" in society \\
\hline 21 & Employment and independent living of individuals with ASDs \\
\hline
\end{tabular}

Table 2. Important points to be discussed among a variety of people. 
The agenda covers various aspects of issues relating to ASDs and society. The following issues were addressed: society and public services (1 and 2), understanding regarding people with ASDs and their families, and relationship-building among individuals with and without ASDs (3 and 5), education and support corresponding to individual differences (4), and employment and independent living of individuals with ASDs (21). Some people considered social attitudes/views toward ASDs, especially discrimination, as important (17 and 18). A broader consideration of the relationship between disabilities, including ASDs, and society was also pointed out as worthy of discussion (19). With regard to information covering ASDs, methods, targets, and the content of the knowledge disseminated to society $(6,7$, and 9) were all topics considered important, as were the positive and negative influences of these disseminations (8). As for ASD research, the issues surrounding a cure for ASDs, as well as the problems regarding the diagnosis of ASDs, were considered important $(12,13$, and 14). The relationship between individual personalities and ASDs was also addressed (15). The necessity for dialogue among a variety of people was mentioned (16). Some people pointed out that balancing a cure for ASDs and the co-existence of people with ASDs (19) was important. While we have tried to create clear classifications without overlap, some items on the agenda were not always totally mutually exclusive by nature of their content.

Limitations: several unavoidable limitations were involved in our agenda-making process. The agenda was the result of limited discussions among a limited number of people within a limited framework; as such, the agenda does not necessarily represent a comprehensive list of all possible issues regarding the societal perspective of ASDs.

First, our participants are not demographically diverse. Second, the content of the discussions and information provided in each dialogue were another source of bias. Third, time limitations were a factor in all the dialogues; therefore, the dialogues experienced by each participant may not have always been sufficient. In other words, our participants may not have received enough or truly balanced scientific information regarding ASDs. Fourth, we did not define any words and phrases in our dialogues and questionnaires for fear of disturbing their tone and because we wanted the participants to be on an equal footing. Thus, the agenda contains various ambiguities regarding the meanings of words and phrases.

The last, and possibly the most important, point is the framing of the primary question, i.e., an "autismfriendly society". Although our respondents were free to express their opposition to the concept of an autism-friendly society (e.g., they could say, "I think it is unnecessary to construct such a society" when completing the questionnaire), the framing of an "autism-friendly society" might be a strong bias for the participants.

\section{Conclusions}

In this paper, we presented a social agenda consisting of various peoples' points of views to improve the relationship between ASDs and society, alongside the scientific advancements in ASD research. This includes a wide range of issues, from practical issues in peoples' daily lives where urgent action is needed, to broader issues for which ongoing, continuous considerations are necessary. For example, issues directly related to ongoing research, like finding a cure for ASDs, were mentioned as worthy of discussion. The advantages and disadvantages of an ASD diagnosis, and the issues related to information regarding ASDs were also included in the agenda. Seemingly, a variety of discussions and dialogues over each issue in our agenda is required. Discussions on the societal aspects of ASD science are important not only in Japan but also worldwide, because advancements in the science of ASDs are occurring internationally. For example, two important papers in the United Kingdom describing important issues regarding the ethical and societal aspects of sciences of ASDs were published in 2011. In one of these papers, Walsh et al. (2011), clearly described issues emerging from the development of biomarkers for ASDs. ${ }^{16}$ Most of the discussion points mentioned in this work were also included in our agenda (e.g., diagnosis, information transmission and communication regarding ASD information, research directions, ambiguity and diversity in the definitions of ASDs, personality, and the importance of partnerships among a variety of people). The other paper was presented by Pellicano and Stears (2011), ${ }^{15}$ and part of this work was inspired by a discussion among ASD researchers, members of ASD advocacy groups, and autistics themselves. After describing the present situation (i.e., ASD sciences are inextricably linked with the values of a variety of people) and then pointing out that public engagement with ASD research is 
inevitable, the paper addressed issues associated with ASDs in society. We found many common points between the topics mentioned in the paper and our agenda based on the perspectives of Japanese people, including research direction, cure, therapy and treatment, diagnosis, boundaries between individual disorders in ASDs, and personality.

Unlike these two papers, which mainly covered the perspectives of researchers and people who have a close relationship with ASDs, our agenda in the present paper was developed based on a mixture of perspectives, most of which came from members of the general public in Japan. The similarities among the issues found in our agenda (i.e., based on the viewpoints of the general public and a few researchers) and the issues highlighted in the papers written by the UK researchers (i.e., inspired by discussions among mostly academicians) could justify the consideration of, and actions towards, those issues related to the relationship between ASDs and society. Although presently it is difficult to draw strong conclusions by making simple comparisons between the situations in the two countries. In addition, similarities related to the need for discussion do not always point to the existence of similarities in the consequences drawn from the discussions.

The purpose of the present study was to construct a social agenda regarding the current and future societal perspective of ASDs. Hence, we did not schedule any direct implementation of the agenda with exception of using it as ice-breaking material for group discussions on the third day of the dialogue entitled "Autism dialogue: Messages from citizens for scientists and society" (see the Methods section). Several events have been held in the Kanazawa area of Japan to discuss the relationship between ASDs and society with citizens and scientists. Although these events could be indirectly influenced by the present agenda, the TAS executive did not take further steps to formally use the agenda.

In summary, our study demonstrated a variety of issues related to the ongoing relationship between ASDs and society, with implications for today and the future. Most of the items included on our agenda would be not unique to the cultural, societal, or institutional aspects of Japan. In other words, each item on our agenda regarding the relationship between ASDs and society could be discussed in societies all over the world. However, in these cases, consideration will need to be given to the various cultural, societal, and institutional aspects that may lead to different consequences compared with those in Japan. ASD science has produced scientific knowledge that has had a significant influence on our society; therefore, discussions and dialogues concerning the science of ASDs and society are becoming increasingly important. We would expect the 21 issues clarified in this study to serve as stepping-stones to develop a better relationship between autism sciences and society.

\section{Acknowledgements}

The authors would like to thank all the participants in the dialogues. We would also like to thank those people, especially Aki Kuwana, who gave us valuable advice and assistance at various stages of organizing the dialogues. This work was supported by: (1) the JSPS Institutional Program for Young Researcher Overseas Visits, (2) Grant-in-Aid for Scientific Research for Jin Higashijima (22800024) and (3) the Japan Ministry of Education, Culture, Sports, Science \& Technology (MEXT) Research Institute of Science \& Technology for Society (Toward autism-friendly society: dialogue on science \& ethical, legal, social and economic issues concerning Autism Spectrum Disorders).

\section{Notes and references}

1 D.J. Kevles (1995), Eugenic Enactments, in In the name of eugenics: genetics and the uses of human heredity, Harvard University Press, Harvard, U.S.A., pg. 96-112.

2 T. Duster (2006), Behavioral genetics and explanations of the link between crime, violence, and race, in E. Parens, A.R. Chapman and N. Press eds., Wrestling with behavioral genetics: science, ethics and public conversation, The Johns Hopkins University Press, Baltimore, U.S.A. pg. 150-175.

3 M. Lock (2008), Biomedical technologies, cultural horizons, and contested boundaries, in E.J. Hackett, O. Amsterdamska, M. Lynch and J. Wajcman eds., The handbook of science and technology studies, third edition, The MIT Press, pg. 875-900.

4 A. Lakoff (2008), The right patients for the drug: pharmaceutical circuits and the codification of illness, in E.J. Hackett, O. Amsterdamska, M. Lynch and J. Wajcman eds., The handbook of science and technology studies, third edition, The MIT Press, pg. 741-759. 
5 H. Geerlings and K. David (2008), Engagement and translation: perspective of a natural scientist, in K. David and P.B. Thompson eds., What can nanotechnology learn from biotechnology?: social and ethical lessons for nanoscience from the debate over agrifood biotechnology and GMOs, Academic Press, pg. 189-219.

${ }^{6}$ B.K. Rothman (2009), Introduction, in P. Atkinson, P. Glasner and M. Lock eds., Handbook of genetics and society: mapping the new genomic era, Routledge, Taylor \& Francis, pg. 401-403.

7 K. Gavelin, R. Wilson and R. Doubleday (2007), Democratic technologies?: the final report of the Nanotechnology Engagement Group (NEG), Involve, London, U.K. http://www.involve.org.uk/democratic-technologies/.

8 J. Tait (2009), Upstream engagement and the governance of science: the shadow of the genetically modified crops experience in Europe, EMBO reports 10: S18-S22, http:/www.nature.com/embor/journal/v10/n1s/full/embor2009138.html.

9 M. Rask and R. Worthington (2012), Towards a new concept of global governance, in M. Rask, R. Worthington and M. Lammi eds., Citizen participation in global environment governance, Routledge.

${ }^{10} \mathrm{http}: / / \mathrm{www}$. wwviews.org/.

${ }^{11} \mathrm{http}: / /$ www.sciencewise-erc.org.uk/cms/.

${ }^{12}$ N. Mikami, S. Sugiyama, Y. Takahashi, T. Yamaguchi and M. Tachikawa (2009), Is a consensus conference applicable to "upstream engagement"?: Nano TRI in Food Nanotechnologies (in Japanese), Japanese Journal of Science Communication 6: 34-49, http://costep.hucc.hokudai.ac.jp/nanotri/.

${ }^{13}$ Editorial (2011), The mind's tangled web, Nature 479(7371): 5 (03 November 2011).

${ }^{14}$ J. Higashijima, C. Nakagawa, Y. Yamanouchi et al. (2012), Public dialogue on Autism and society in Japan (in Japanese), Japanese Journal of Science Communication 11: 28-43.

${ }^{15}$ E. Pellicano and M. Stears (2011), Bridging autism, science and society: moving toward an ethically informed approach to autism research, Autism Research 4(4): 271-282.

${ }^{16}$ P. Walsh, M. Elsabbagh, P. Bolton and I. Singh (2011), In search of biomarkers for autism: scientific, social and ethical challenges, Nature Reviews Neuroscience 12: 603-612.

${ }^{17}$ M.H. Nadesan (2005), Constructing autism: unravelling the 'truth' and understanding the social, Routledge.

${ }^{18}$ B. Goldacre (2007), MMR: the scare stories are back, BMJ 335: 126-127.

${ }^{19} \mathrm{~K}$. Weintraub (2011), The prevalence puzzle: Autism counts, Nature 479: 22-24.

${ }^{20}$ H. Coo, H. Ouelette-Kuntz, J.E.V. Lloyd, L. Kasmara, J.J.A. Holden and M.E.S. Lewis (2008), Trends in Autism Prevalence: diagnostic substitution revisited, Journal of Autism and Developmental Disorders 38(6): 1036-46.

${ }^{21}$ M.F. Blaxill (2004), What's going on? The question of time trends in Autism, Public Health Reports 119: 536-551.

${ }^{22}$ C.J. Newschaffer, M.D. Falb and J.G. Gurney (2005), National autism prevalence trends from United States special education data, Pediatrics 115: e277-e282.

${ }^{23}$ American Psychiatric Association (2000), Diagnostic and Statistical Manual of Mental Disorders DSM-IV-TR

${ }^{24}$ Autism and Developmental Disabilities Monitoring Network Surveillance Year 2006 Principal Investigators, Centers for Disease Control and Prevention (2009), Prevalence of autism spectrum disorders - Autism and Developmental Disabilities Monitoring Network, United States, 2006, MMWR Surveillance Summaries 58(SS-10): 1-20.

${ }^{25}$ Autism and Developmental Disabilities Monitoring Network Surveillance Year 2006 Principal Investigators, Centers for Disease Control and Prevention (2010), Errata: Prevalence of autism spectrum disorders - Autism and Developmental Disabilities Monitoring Network, United States, 2006, MMWR Surveillance Summaries 58(SS-10): 1-20, MMWR Surveillance Summaries 59(30): 956.

${ }^{26}$ M. Knapp, R. Romeo and J. Beecham (2007), The economic consequences of autism in the U.K., Foundation for People with Learning Disabilities, London, U.K., http://eprints.lse.ac.uk/3462/.

${ }^{27}$ D. Newman (2011), Special issue on neuroscience: the Autism enigma, Nature 479: 21

${ }^{28}$ World Health Organization (1990), International Statistical Classification of Diseases 10 , http://www.who.int/classifications/icd/en/.

${ }^{29}$ Interagency Autism Coordinating Committee (2011), NIH Workshop: Ethical, Legal and Social Implications of Autism Research, http://iacc.hhs.gov/non-iacc-events/2011/elsi-workshop-biosketches-sept26.shtml.

${ }^{30}$ E. Yagi and C. Nakagawa (2011), Proposal of the science café methods to enhance participants' discussion: opinion eliciting workshops about science and technology issues (in Japanese), Communication-Design 4: 47-64.

${ }^{31}$ Website of the research project entitled "Autism-friendly society: a search for reconciling the coexistence and the cure of autism”: http://ristex-kanazawa.w3.kanazawa-u.ac.jp/pdf/eng.pdf.

\section{Authors}

Jin Higashijima Ph.D. is a Research Fellow of the Japan Society for the Promotion of Science (Osaka University) and was a member of a research project aiming to promote dialogues between researchers and public regarding Autism Spectrum Disorders. E-mail: Jin@let.osaka-u.ac.jp.

Yui Miura is an Assistant Professor at the Research Center for the Child Mental Development, Kanazawa University in Japan. She is a developmental psychologist participates in a project on setting up a dialogue between scientists and citizens about the issues of autism. E-mail: yui@staff.kanazawa-u.ac.jp. 
Chie Nakagawa Ph.D. is a graduate student of the Graduate School of Biostudies, Kyoto University, Japan. She has studied the relationship between science and society, particularly focusing on methods of public participation. E-mail: cnakagawa.d08@lif.kyoto-u.ac.jp.

Yasunori Yamanouchi Ph.D. is an Adjunct Assistant Professor of Center for the Study of Communication-Design, Osaka University, Japan. He is a member of a Program for Education and Research on Science and Technology in Public Sphere. E-mail: yamanouchi@cscd.osaka-u.ac.jp.

Kae Takahashi M.S. graduated the Graduate School of Biostudies (Kyoto University) and Communicators in Science and Technology Education Program (Hokkaido University) in Japan. She is an administrative staff member in a research institute and interested in the relationship between science and society. E-mail: kaet@jamstec.go.jp.

Masaki Nakamura Ph.D. is an Associate Professor at Center for Education in Liberal Arts and Sciences, Osaka University, Japan. His research interests include science communication, research integrity, and science policy.E-mail: masaki@celas.osaka-u.ac.jp.

How TO CITE: J. Higashijima, Y. Miura, C. Nakagawa, Y. Yamanouchi, K. Takahashi and M. Nakamura, Public opinions regarding the relationship between Autism Spectrum Disorders and society: social agenda construction via science café and public dialogue using questionnaires, Jcom 11(04) (2012) A03. 